Trinity University

Digital Commons @ Trinity

Psychology Faculty Research

Psychology Department

1983

\title{
Bonuses and Bribes: Mood Effects in Memory
}

\author{
A. K. Boggiano \\ Paula T. Hertel \\ Trinity University, phertel@trinity.edu
}

Follow this and additional works at: https://digitalcommons.trinity.edu/psych_faculty

Part of the Psychology Commons

Publication Details

Social Cognition

\section{Repository Citation}

Boggiano, A.K., \& Hertel, P.T. (1983). Bonuses and bribes: Mood effects in memory. Social Cognition, 2(1), 49-61.

This Article is brought to you for free and open access by the Psychology Department at Digital Commons @ Trinity. It has been accepted for inclusion in Psychology Faculty Research by an authorized administrator of Digital Commons@ Trinity. For more information, please contact jcostanz@trinity.edu. 


\title{
BONUSES AND BRIBES: MOOD EFFECTS IN MEMORY
}

\author{
ANN K. BOCGIANO \\ University of Colorado \\ PAULA T. HERTEL \\ Trinity University
}

\begin{abstract}
Free recall of emotionally positive, neutral, and negative adjectives was used as an indirect assessment of the effects of reward on expectations about intrinsic interest. Reward for performing later activities described as interesting (a "bonus" orientation) produced recall of a greater number of emotionally positive adjectives, whereas reward for the same activities described as boring (a "bribe" orientation) produced recall of a larger number of negative adjectives. A cuedexpectancy analysis suggests that reward serves to polarize initial attitude about forthcoming tasks; these polarized attitudes, like moods, influence the nature of words retrieved from memory.
\end{abstract}

Recently, the interplay of social and cognitive psychology has provided some challenging questions and initial answers about the interaction of affective and cognitive states. From one perspective, a number of researchers have been concerned primarily with the effect of mood on memory structures and processes (Bower, 1981; Isen, Shalker, Clark, \& Karp, 1978; Leight \& Ellis, 1981). On the other side of this coin, much research has been directed at understanding how memory structures and processes affect social phenomena, such as person perception and attitude change (Hamilton, 1979). In this paper, we wish to emphasize the reciprocity of these two approaches to the study of social cognition. By juxtaposing a memory task and a manipulation of intrinsic interest and extrinsic reward, our intent was to show mood effects on memory and the dual implications that these effects might have for cognitive theory and a theory of attitude polarization.

Attitude polarization has been proposed as an initial step in the cued-

Requests for reprints should be sent to Ann K. Boggiano, Department of Psychology, University of Colorado, Boulder, Colo. 80309. 
expectancy analysis of the effect of positive incentives on continued interest in activities (Boggiano, 1981)-a phenomenon commonly referred to as the "overjustification effect" (Deci \& Ryan, 1980; Lepper \& Greene, 1978; Pittman, Boggiano, \& Ruble, 1983). According to cued expectancy, reward affects subsequent interest in the following manner. First, reward polarizes or strengthens initial expectations about the interest value of a forthcoming activity. That is, reward anticipated in the context of a task made to appear highly interesting should be interpreted as a bonus and should cue even more positive feelings about the activity to be performed. Likewise, reward provided in the context of the same task made to appear uninteresting should be interpreted as a bribe and thus should intensify negative feelings about the interest value of the task. Even in very young children, subsequent interest has been shown to depend on interpretation of the meaning of reward (Boggiano, Narackiewicz, Main, \& Bessette, 1983; Boggiano \& Ruble, 1979; Boggiano, Ruble, \& Pittman, 1982; Lepper, Sagotsky, Dafoe, \& Greene, 1982; Pittman, Emery, \& Boggiano, 1982). To illustrate this phenomenon, a valued prize provided for going on a blind date with an attractive partner would be expected to generate positive feelings and might even heighten expectations regarding enjoyment. But the same incentive offered for dating an unattractive other might have the opposite effect.

The second component of cued expectancy involves contrast effects produced because of these extreme standards of comparison against which the actual activity is evaluated. Polarized positive attitudes before task engagement ultimately produce dissatisfaction and negative judgments about the actual activity, due to contrast with the high initial standard. Conversely, polarized negative attitudes before task engagement ultimately produce positive judgments about the same activity because of contrast with initially low standards.

These predictions about the importance of internal states (e.g., feelings or initial attitudes) on subsequent attitudes differ markedly from a self-perception analysis of the effect of reward on later interest. Since a self-perception analysis argues that final attitudes depend primarily on interpretation of behavior and on the context in which the behavior occurs, direction or strength of initial attitudes (e.g., attitude about the interest value of the activity) should be irrelevant in determining later attitudes (Bem \& McConnell, 1970; Greene, 1974). From a self-perception perspective, then, reward should decrease interest, regardless of whether the task is manipulated to be perceived as interesting or boring. Thus, the hypothesized effect of strength or extremity of initial attitude in determining later attitude differs substantially from the self-perception model. Research testing these different predictions provides support for the cued expectancy model but not for the self-perception model (Boggiano, 1981). 
However, although behavioral evidence has been provided for contrast as a component of this process, attitude polarization has received some support only from attitudinal evidence, in the form of shifts in rated interest. Since researchers in the area of the effect of rewards on interest have generally preterred unobtrusive measures of interest (e.g., behavioral measures) as opposed to less obtrusive attitudinal measures for several reasons (Deci \& Ryan, 1980; Pittman et al., 1982; Smith \& Pittman, 1978), a more sensitive and perhaps more central way to examine the attitude polarization component of cued expectancy would be to assess the content of current thought and its relationship to a bribe-versus-bonus orientation. Since a bonus orientation may produce positive feelings, similarly positive information in memory should be more accessible than other information (Isen et al., 1978). Measuring anticipated interest in an activity by assessing recall of material in memory unrelated to the target activity could therefore test attitude polarization unobtrusively and could also avoid potential problems associated with examining interest by attitudinal measures. From a cued-expectancy perspective, then, reward provided in the context of an interesting task description, generating a bonus orientation, should make a good mood even better and should lead to increased recall of positive affective material in comparison to no-reward, interesting task control. In contrast, the feelings evoked by reward under circumstances associated with a bribe orientation would not be assumed to generate positive thoughts, but rather to facilitate the recall of emotionally negative material. This analysis would suggest that content of current thought should be congruent with mood state determined by these different orientations.

These predictions for differential effects of mood on memory, depending on interpretation of the meaning of reward, are generally consistent with other theoretical orientations to an affective-cognitive interaction. For example, Bower's (1981) associative-network theory of emotion and memory would predict that negative or positive emotion nodes are primed by the bribe or bonus orientation and that activation from the emotion nodes would spread to word nodes labeling the emotion and to event nodes associated with the emotion. This spreading activation would thereby prime emotion-associated material in memory, making it more easily drawn upon than other information. Such a model for affectivecognitive interactions is supported by a growing and diverse body of memory research (cf. Bower, 1981).

However, much of the data can be explained by invoking the effect of cueing different categories on behavior (e.g., giving or not giving a gift), rather than the effect of mood on memory (lsen, 1982). For example, it is possible that the use of categories such as a gift versus no gift produced differential recall of events, independent of mood state. One means of testing whether mood and not simply the cueing ot different categories accounts 
for behaviors such as recall of positive versus negative events is to use the same category (e.g., a gift of money) to induce different mood states, depending on condition. By using the paradigm of attitude polarization, the hypothesized effect of mood on memory would be supported if the effect of the same reward on recall of positive and negative events resulted from the feelings evoked by reward, depending on contextual conditions, and not from the mere presence or absence of reward.

In the following experiment, the hypothesis that bribes and bonuses, depending on interpretation of reward, affect the content of current thought was assessed first by presenting a list of emotionally positive, negative, and neutral words before the manipulation of interest in an alleged forthcoming task (i.e., the target task), and then by requiring free recall of this list after the task description. The target task was described to subjects as either interesting or boring, or interest value was not described. In addition, subjects were either promised reward or given no such promise for performance in the forthcoming task. From the standpoint of a possible affective-cognitive interaction, the recall frequency of emotionally positive and negative words was expected to vary according to conditions of interest value and reward, thereby demonstrating attitude polarization on the one hand, and mood affects in memory on the other.

\section{METHOD}

\section{SUBJECTS}

A total of 92 students ( 43 males and 53 females) from Fordham University were recruited on a volunteer basis to serve as subjects for an experiment allegedly concerned with decision making. Subjects were run individually by either a male or a female experimenter (both of whom were blind to the hypotheses) and randomly assigned to one of six between-subjects conditions; two levels of reward (reward or no reward) were crossed with three levels of manipulated interest value of the activity to be performed (high, control, or low). The within-subjects factor of word type contained three levels (positive, neutral, or negative).

\section{MATERIALS}

Words for the memory task were selected from Anderson's (1968) likableness ratings of personality-trait words. Eight positive words (e.g., "kind," "friendly," "helpful") were chosen from words producing likableness ratings of $\mathbf{4 7 5}$ or above; the eight negative words (e.g., "cold," "hostile," "greedy") were rated 175 or below. Fourteen neutral words ("careful," 
"thrifty," "quiet") produced likableness ratings between 400 and 200; six of the 14 neutral words were selected for the three beginning and the three end positions on the list (fillers), and were more extreme within the range of likable ratings. but were not scored at recall. All words received meaningfulness ratings of 350 or above. Finally, we chose words producing a small $(<1.00)$ variance in likableness ratings and counterbalanced word length within word type.

Four different orders of the resulting list of 24 words were constructed (with the constant filler words at beginning and end). Word type was counterbalanced within blocks of six words, and consecutively occurring words of the same type were not permitted. These lists were then taped with a 2 -second interval between words.

\section{PROCEDURE}

Subjects were told that they were participating in a study designed to test purportedly the effect of performing different activities on the decisionmaking process. While one of a variety of activities was allegedly being prepared, the subject was approached in the waiting room and asked to help a graduate student with a short delayed-recall experiment. When the subject agreed (all did), a taped list of adjectives was presented with instructions to listen carefully.

During the retention interval of 5 minutes, more information allegedly concerning the decision-making task was provided. Subiects in the high-interest-value condition (cf. Boggiano, 1981) were told that, of the many different activities included in the study, they "fortunately" had been assigned to do an exciting task. Those in the low-interest-value condition were told to expect an extremely tedious and monotonous activity. No information concerning task interest value was offered to subjects assigned to the control condition. Subjects selected to receive a reward were then given $\$ 1.50$ for participation. (Those in the no-reward condition were paid the same amount during the debriefing.) Finally, before leaving the waiting room to participate in the alleged decision-making task, the subject was asked to engage in free recall of the list of words; guessing was encouraged. All subjects were debriefed and dismissed following recall and assessment of the manipulation of the interest value of the task.

\section{RESULTS}

\section{RECALL}

The first three rows of Table 1 present the mean number of positive, neutral, and negative words recalled by subjects in each condition of reward 
TABLE 1

Mean Number of Words of Each Type Recalled

\begin{tabular}{|c|c|c|c|c|c|c|}
\hline \multirow[b]{3}{*}{ WORD TYPE } & \multicolumn{6}{|c|}{ INTEREST VALUE } \\
\hline & \multicolumn{2}{|c|}{ INTERESTING } & \multicolumn{2}{|c|}{ NEUTRAL } & \multicolumn{2}{|c|}{ BORING } \\
\hline & REWARD & $\begin{array}{c}\text { NO } \\
\text { REWARD }\end{array}$ & REWARD & $\begin{array}{c}\text { NO } \\
\text { REWARD }\end{array}$ & REWARD & $\begin{array}{c}\text { NO } \\
\text { REWARD }\end{array}$ \\
\hline Positive & 3.43 & 2.47 & 2.50 & 2.00 & 2.33 & 1.88 \\
\hline Neutral & 1.57 & 1.87 & 2.13 & 1.94 & 2.73 & 1.38 \\
\hline Negative & 1.71 & 2.00 & 1.94 & 1.94 & 3.07 & 2.13 \\
\hline $\begin{array}{l}\text { Positive minus } \\
\text { negative words }\end{array}$ & 1.72 & .47 & .56 & .06 & -.74 & -.25 \\
\hline
\end{tabular}

and interest value. The data from the mixed design were submitted to an analysis of variance, which revealed a reliable three-way interaction of word type, reward, and interest value, $F(4,172)=2.48, M S_{e}=.995$. (The significance level was set at .05 for all analyses.) This interaction corresponds directly with our central prediction that the combination of reward and interest value produced a feeling (bonus or bribe) that, in turn, cued recall of mood-related material. The interaction of task conditions differentially affected the type of words recalled. This three-way interaction is seen more easily in the last row of Table 1, which describes the difference between positive and negative word recall (omitting neutral words) for each between-subjects condition. An analysis of the effect of reward and three levels of interest value on positive words minus negative words revealed a marginally significant interaction, $F(2,91)=2.94, M S_{c}=1.92$, $p<.06$; the interaction was reliable when the analysis included reward and two levels of interest value (excluding the neutral condition), $F(1,59)=$ $6.24, M S_{e}=1.92$. Thus, reward was found to have different effects on the type of word recalled, depending on the interest value established for the task.

Guided by predictions concerning the polarization effects of reward, further analyses explored differences within each condition of interest value, using all cells in the design. In the interesting-task condition, subjects differentially recalled positive, neutral, and negative words, depending upon their expectation about reward, $F(2,172)=3.25, M S_{c}=.995$. Furthermore, reward facilitated the recall of positive words only, $F$ ( 1 , $172)=4.99, M S_{c}=.995$. For the task condition in which interest value was not manipulated (neutral), differences were not statistically reliable, as ex- 
pected. And, although differences in the boring-task condition were not as large as those in the interesting-task condition, reward nevertheless increased the recall of negative words, $F(1,172)=4.67, M S_{e}=.995$. This difference, however, must be viewed somewhat cautiously, given the lack of a reliable interaction of word type with reward in the boring-task condition and the obvious facilitation for recall of neutral words in that condition. Yet, the reward effect on recall of negative words in the boring-task condition is suggestive, especially when it is compared to the other two task conditions, which show no increase on negative recall as a function of reward. In this vein, the interaction of reward with interest value for recall of negative wordswas reliable, $F(2,172)=3.14, M S_{e}=.955$. Thus, reward increased both the recall of emotionally positive words when subjects were expecting to participate in an interesting task, and the recall of emotionally negative words when subjects believed a boring task was allegedly forthcoming.

In addition to the three-way interaction, other reliable effects were revealed by the overall analysis. First, the interest value of the task interacted with word type, $F(4,172)=5.71, M S_{e}=.995$; an inspection of the mean suggests that subjects in the interesting task tended to recall more positive words, whereas those in the boring task recalled more negative words. Second, more positive words were recalled across all conditions, $F(2$, $172)=5.84, M S_{e}=.995$; and reward facilitated recall, $F(1,86)=5.91$, $M S_{e}=2.106$.

\section{INTEREST MANIPULATION}

Table 2 presents the average rated interest in the forthcoming task for each experimental condition. The interest value of the task, as described, did indeed affect rated interest, $F(2,86)=24.30, M S_{e}=18.325$; and although the reward factor did not reliably interact with interest value, the trend was in the direction of differences in the memory task. Rated interest appeared to

TABLE 2

Average Rat ed Int erest in the Forthcoming Task

\begin{tabular}{lccc}
\hline & \multicolumn{3}{c}{ INTEREST VALUE } \\
\cline { 2 - 4 } REWARD CONDITION & INTERESTING & NEUTRAL & BORING \\
\hline Reward & 16.50 & 14.56 & 8.13 \\
No reward & 15.00 & 14.75 & 9.13 \\
\hline
\end{tabular}


decrease for the boring task and increase for the interesting task when reward was offered. The strength of the effect of reward on expectancies about task interest, in comparison to its effect on recall of positive or negative word type, may be due to demand characteristics. In the interest-rating task, subjects may have attempted to respond in a manner to verify the experimenter's description of the activity more than to reflect their mood. The strength of the main effect of interest value is consistent with this explanation.

\section{DISCUSSION}

Two reciprocal conclusions emerge from these results. Qualitative differences in recall were established by nonreactive mood induction procedures, and the nature of the recall differences support the attitude polarization component of cued-expectancy theory. More specifically, subjects who were "bribed" with a reward to perform an allegedly uninteresting task recalled a larger number of negative words, presumably reflecting their "bad mood," whereas those receiving a bonus reward to perform an interesting task recalled a larger number of positive words, reflecting their "good mood." Clearly, the results suggest an important link between the attitude polarization effects of reward and the affective-cognitive interaction known as mood state. Furthermore, unlike a number of previous findings (e.g., Bower, 1981), the data are not easily interpreted by means of a demand explanation.

From the standpoint of cued-expectancy theory, it is interesting to note that while differences in memory for affective material support the attitude polarization component, ratings of task interest did not. These differences in behavioral versus attitudinal measures parallel findings in the overjustification literature (Pittman et al., 1982; Smith \& Pittman, 1978). As suggested by a number of researchers (e.g., Nisbett \& Wilson, 1977; Smith \& Pittman, 1978), subjects may not have access to the processes that mediate their behavior. Thus, feelings about the activity to be performed may have been polarized without subjects being aware of their feelings. Alternatively, a demand explanation may account for subjects' responses in the interest-rating task.

With regard to differences in memory for affective material, it would appear unlikely that subjects deliberated carefully about the effect reward had on their mood when retrieving information from memory. According to theoretical analyses of the effect of mood state on behavior (Clark \& Isen, 1982), mood is assumed to influence judgment much of the time with- 
out conscious awareness. Such "automatic processing" effects may occur in a nonreflective manner and may affect our impressions of both people and objects (Schneider, Hastorf, \& Ellsworth, 1980; Zajonc, 1980). From this perspective, even thinking about favorable or unfavorable events may polarize attitudes about those events (e.g., Tesser, 1978), since thoughts congruent with affect associated with those events would come to mind and intensify initial attitude about the events. Thus, a feeling state may automatically activate affect-congruent thoughts about an event, which may both intensify initial feelings about that event and increase the likelihood that one will behave in a manner consistent with that feeling state. This line of reasoning suggests the process by which mood state may be maintained.

Although automatic processing may account for the effect of positive mood state on behavior, it does not appear consistent with the body of research examining the effect of negative feelings on judgments and behavior. That is, while a positive feeling state has generally been found to increase the probability of drawing upon positive material in memory and behaviors such as helping and generosity (Aderman, 1972; Batson, Coke, Chard, Smith, \& Taliaferro, 1979; Cunningham, Steinberg, \& Grev, 1980; Isen, 1970; Isen, Clark, \& Schwartz, 1976; Isen \& Levin, 1972; Levin \& Isen, 1975; Mischel, Ebbesen, \& Zeiss, 1973; Moore, Underwood, \& Rosenhan, 1973; Underwood, Froming, \& Moore, 1977; Weyant, 1978), the effects of negative feeling states are far more complex. Some studies suggest that inducing negative mood states increases the likelihood of antisocial behaviors (Baron, 1972; Baron \& Bell, 1975), whereas others suggest that negative affect either has no effect or increases the likelihood of positive behaviors (Carlsmith \& Gross, 1969; Cialdini, Darby, \& Vincent, 1973; Cialdini \& Kenrick, 1976; Isen, 1970; McMillen, 1971; Mischel, Coates, \& Raskoff, 1968; Mischel \& Moore, 1973; D. T. Reagan, Williams, \& Sparling, 1972; J. W. Regan, 1971; Teasdale \& Fogarty, 1979; Underwood, Moore, \& Rosenhan, 1973).

The data on the effect of negative feeling states on behavior have been interpreted as suggesting that, unlike positive feeling states, in which mood is often automatically maintained, negative feeling states may well motivate people to control or change their mood state (Clark \& Isen, 1982). In this sense, people exposed to negative mood induction may attempt to alter their mood state by thinking or behaving in a positive way. Although this analysis is consistent with the findings of much research, it does not explain why negative mood will increase the likelihood of antisocial behaviors or make negative material from memory more accessible, as shown to some extent in the present study. 
Although highly speculative, the following hypothesis is offered to account for the differential effects of negative mood states on judgments and behavior. The majority of studies manipulating negative mood state would appear to have produced shame, sadness, or depression. For example, failure in a task would presumably induce feelings of shame or sadness (Isen et al., 1978). Other researchers have explicitly told subjects to think about sad events (e.g., Teasdale \& Fogarty, 1979; Underwood et al., 1973) or have prompted subjects to commit some transgression (e.g., Cialdini et al., 1973). The results of this body of research indicate that subjects behaved in a positive way (e.g., helping), presumably to alleviate the shame or to compensate for failure.

In contrast, negative mood states involving anger rather than sadness may produce somewhat different effects. Like individuals who feel sad or ashamed, those who feel angry may also be motivated to change their mood state. However, the strategy employed for this purpose may involve some form of catharsis; subjects may attempt to redirect angry feelings. Specifically, individuals who feel angry may think about other negative events or perform negative behaviors to release their angry feelings, at least for a brief time following the anger-inducing event (e.g., Baron, 1972; Baron \& Bell, 1975). Alternatively, anger may be located conceptually on a continuum of controlled to automatic maintenance, somewhere between positive feelings and sadness. Anger may be more automatically maintained than feelings of sadness, especially for those who have not learned to control their angry feelings. Finally, anger may simply produce stronger negative feelings than sadness or shame, making it much more difficult to behave or think positively.

Thus, one perspective on the effects of negative mood state on the recall results of this study is to view the bribe condition as producing feelings better described as anger than as sadness. Subjects temporarily maintained their angry feelings, either automatically or purposefully (to release them). Consequently, their negative quality influenced the content of thought, including retrieval of negative words. This interpretation may be contrasted with predictions regarding sad mood states evoked by manipulations that are not bribe-oriented. Implications of these findings about the effect of negative mood states should be considered on a cautionary note, of course, since our findings about negative feelings were substantially smaller than the findings regarding the effect of positive mood state on memory. However, this perspective does contribute testable implications for individual differences in mood effects on memory, determined perhaps by the degree of anger or sadness that individuals feel in a common situation. 


\section{REFERENCES}

Aderman, D. Elation, depression, and helping behavior. Joumal of Personality and Social Psychology, 1972, 24, 91-101.

Anderson, N. H. Likeableness ratings of 555 personality-trait words. Joumal of Personality and Social Psychology, 1968, 9, 272-279.

Baron, R. A. Aggression as a funcion of ambient temperature and prior anger arousal. Journal of Personality and Social Psychology, 1972, 21, 183-189.

Baron, R. A., \& Bell, P. A. Aggression and heat: The influence of ambient temperature, negative affect, and a cooling drink on physical aggression. Joumal of Personality and Social Psychology. 1975, 33, 245-255.

Batson, C. D., Coke, J. S., Chard, F., Smith, D., \& Taliaferro, A. Generality of the "glow of goodwill": Effects of mood on helping and information acquisition. Social Psycholo8y Quarterly, 1979, 42, 176-179.

Bem, D., \& McConnell, H. K. Testing the self-perception explanation of dissonance phenomena: On the salience of premanipulations attitudes. Joumal of Personality and Social Psychology, 1970, 14, 23-31.

Boggiano, A. K. Self-perception versus cued-expectancy: Analyses of the effects of reward on task interest. Paper presented at the meeting of the American Psychological Association, 1981.

Boggiano, A. K., Narackiewicz, J. M., Main, D. J., \& Bessette, J. M. Increasing children's intrinsic interest through performance contingent reward. Paper presented at the meeting of the American Psychological Association, 1983.

Boggiano, A. K., \& Ruble, D.N. Competence and overjustification: A developmental study. Jormal of Personality and Social Pychology, 1979, 37, 1462-1468.

Boggiano, A. K., Ruble, D. N. \& Pittman, T. S., The mastery hypothesis and the overjustification effect. Social Cognition, 1982, 1, 38-49.

Bower, G. H. Mood and memory. American Psychologist, 1981, 36, 129-148.

Carlsmith, J. M., \& Gross, A. Some effects of guilt on compliance. Joumal of Personality and Social Psychology, 196 9, 11, 240-244.

Cialdini, R., Darby, B., \& Vincent, J. Transgression and altruism: A case for hedonism. Joumal of Experimental Social Psychology, 1973, 9, 502-516.

Cialdini, R. B., \& Kenrick, D. T. Altruism as hedonism: A social development perspective on the relationship of negative mood state and helping. Joumal of Personality and Social Psychology. 1976, 34, 907-914.

Clark, M. S., \& Isen, A. M. Toward understanding the relationship between feeling states and social behavior. In A. Hastorf \& A. Isen (Eds.), Cognitive social psychology. New York: Elsevier-North Holland, 1982.

Cunningham, M. R., Steinberg, J. \& \& Grev, R. Wantingt oand havingto help: Separate motivationsfor positive mood and guilt induced helping. Joumal of Personality and Social Psychology, 1980, 38, 181-192.

Deci, E. L., \& Ryan, R. M. The empirical explanation of intrinsic motivational processes. In L. Berkowitz (Ed.), Advances in experimental psychology (Vol. 13). New York: Academic Press, 1980.

Greene, D. Dissonance and self-perception analysis of "forced compliance": When two theories make competing predictions. Joumal of Personality and Social Psychology, 1974, 29, 819-828.

Hamilton, D. L. A cognitive-attributional analysis of stereotyping. Advances in Experimental Social Psychology, 1979, 12, 53-84. 
Isen, A. M. Success, failure, attention, and reactions to others: The warm glow of success . Journal of Personality and Social Psychology, 1970, 15, 294-301.

Isen, A. M. Personal communication, 1982.

Isen, A. M., Clark, M. \& Schwartz, M. F. Duration of the effect of good mood on helping: "Footprints on the sands of time." Journal of Personality and Social Psychology, 1976, 36, 1-12.

Isen, A.M., \& Levin, P. F. The effect of feeling good on helping: Cookies and kindness. Journal of Personality and Social Psychology, 1972, 21, 384-388.

Isen, A. M., Shalker, T., Clark, M., \& Karp, L. Affect accessibility of material in memory and behavior: A cognitive loop? Journal of Personality and Social Psychology, 1978, $36,58-69$.

Leight, K. A., \& Ellis, H. C. Emotional mood states, strategies, and statedependency in memory. Journal of Verbal Learning and Verbal Behavior, 1981, 20, 251-266.

Lepper, M. R., \& Greene, D. Divergent approaches to the study of rewards. In M. R. Lepper \& D. Greene (Eds.), The hidden costs of reward. Hillsdale, N.J .: Erlbaum, 1978.

Lepper, M. R., Sagotsky, G., Dafoe, J. L., \& Greene, D. Consequences of superfluous social constraints: Effects on young children's social inferences and subsequent intrinsic interest. Journal of Personality and Social Psychology. 1982, 42, 51-65.

Levin, P.F., \& Isen, A . M. Something you can still get for a dime: Further studies on the effect of feeling good on helping. Sociometry, 1975, 38, 141-147.

McMillen, D. L. Transgression, self-image, and complaint behavior. Journal of Personality and Social Psychology, 1971, 20, 176-179.

Mischel, W., Coates, B ., \& Raskoff, A. Effects of success and failure on selfgratification. Journal of Personality and Social Psychology, 1968, 10, 381-390.

Mischel, W., Coates, B., \& Raskoff, A. Effects of success and failure on self-gratification. tional determinants. Journal of Personality and Social Psychology, 1973, 27. 129-142.

Mischel, W., \& Moore, B. Effects of attention to symbolically presented reward upon selfcontrol. Journal of Personality and Social Psychology, 1973, 28, 172-179.

Moore, B. S., Underwood, B., \& Rosenhan, D. L. Affect and altruism. Developmental Psychology, 1973, 8, 99-104.

Nisbett, R. E., \& Wilson, T. D. Telling more than we can know: Verbal reports on mental processes. Psychological Review, 1977, 84, 231-259.

Pittman, T. S., Boggiano, A. K., \& Ruble, D. N. Rewards and intrinsic motivation in children: Implications for educational settings. In J. M. Levine \& M. Wang (Eds .), Perceptions of success and failure: New directions in research. Hillsdale, N.J.: Erlbaum, 1983.

Pittman, T. S., tmery, J., \& Boggiano, A. K. Intrinsic and extrinsic motivational orientations: Reward-induced changes in preference for complexity. Journal of Personality and Social Psychology, 1982, 42, 789-797.

Regan, D.T., Williams, M., \& Sparling, S. Voluntary expiation of guilt: A field experiment. Journal of Personality and Social Psychology, 1972, 24, 422-445.

Regan, J. W. Guilt, perceived injustice, and altruistic behavior. Journal of Personality and Social Psychology, 1971, 18, 142-132.

Schneider, D. J., Hastorf, A. H., \& Ellsworth, P. C. Person perception. Reading, Mass.: Addison-Wesley, 1980.

Smith, T. W., \& Pittman, T. S. Reward, distraction, and the overjustification effect . Journal of Personality and Social Psychology, 1978, 36, 565-572.

Teasdale, J. K., \& Fogarty, S. J. Different effects of induced mood on retrieval of pleasant and unpleasant events from episodic memory. Journal of Abnormal Psychology, 1979. $88,248-257$. 
Tesser, A. Self-generated attitude change. Advances in Experimental Social Psychology. 1978, 11, 289-338.

Underwood, B., Froming, W., \& Moore, B. Mood, attention, and altruism: A search for mediating variables. Experimental Psychology, 1977, 13, 541-542.

Underwood, B., Moore, B. S., \& Rosenhan, D. L. Affect and self-gratification. Developmental Psychology, 1973, 8, 209-214.

Weyant, J. M. Effects of mood states, costs, and benefits of helping. Joumal of Personality and Social Psychology, 1978, 36, 1169-1176.

Zajonc, R. B. Feeling and thinking: Preferences need no inferences. American Psychologist, 1980, 35, 151-175. 